run by dedicated doctors with no community commitments, were in pristine condition. They consisted of individual rooms and a communal area that featured a large aquarium, reading lounge, small library and table tennis table. The doctors wore white coats over casual clothes and the atmosphere was generally relaxed. Despite a policy of separating patients who were severely psychotic from those who were less disturbed, in-patient units faced familiar pressures of bed shortages and social problems delaying discharge. While general, forensic and child and adolescent psychiatry had equivalents in Sweden, the management of organic illnesses such as dementias was left to medical teams. Separate drugs and alcohol services were based in central Stockholm. As might be expected, we found similarities with the biopsychosocial and multidisciplinary approach adopted in the UK, but were impressed with the quality of administrative and logistical support. Trainees had access to individual computers, modern on-call facilities and trendy quarters. A tour of the laboratories revealed common monitoring of psychotropic blood levels and the availability of metabolic profiling.

Recruitment into psychiatry had traditionally been difficult. The number had peaked from the late 1990s and stood at 1400 in 2002 (Silfverhielm \& Stefansson, 2006). After 5 years of medical school and 18 months as house officers, doctors enrol on a 5-year training programme that leads to recognition as specialists. Many trainees we met had recently joined following a successful recruitment campaign based on financial and academic incentives. These included encouragement and funding to train in a range of psychotherapy modalities, a flexible on-call system and research opportunities. In contrast to their British counterparts, residents became actively involved in research early on and were given appropriate time and resources.

We found our visit extremely informative, enjoyable and productive. It highlighted some of the positive aspects of our own clinical practice and provided valuable lessons for the future. We strongly recommend that international visits be incorporated into training at an early stage. They broaden horizons and encourage reflection. They also further links between institutions and professionals that can only benefit service users and the National Health Service.

Joseph El-Khoury and Claire Dillon Senior House Officers, St George's Training Scheme, London, UK, email joelkhoury@yahoo.com

Feinstein, A. (2002) Psychiatry in post-apartheid Namibia: a troubled legacy. Psychiatric Bulletin, 26, 310-312.

Kennedy, P. (2005) Lessons from and for Japan on service delivery. Psychiatric Bulletin, 29, 309-311.

Silfverhielm, H. \& Stefansson, C. G. (2006) Country profile. Sweden. International Psychiatry, 3(1), 9-12.

\section{Tremors within the health system}

S I read with great interest M. M. Khan's paper chiatry', in the July 2006 issue of International Psychiatry (vol. 3, no. 3, pp. 21-23). It was heartbreaking to read of the state of mental health in Pakistan, but hope still remains as long as there are people putting in effort to rectify this. I agree that the Pakistan Psychiatric Society should play a more prominent role than it has up to now.

At the same time, one should not underestimate the difficulties and obstacles in improving standards of mental health in a country where almost a third of the population live below the poverty line. We are also observing an increase in the incidence and prevalence of mental illness in that region, owing to growing insecurity, terrorism, economic problems, political uncertainty, unemployment and disruption of the social fabric. A feudal mind-set exists not only in the rural areas of the country but also in institutions of learning, where established psychiatrists do not promote or help junior doctors, for fear of either increased competition or of being replaced by the younger generation, but this puts patient care at stake. Not enough effort is being directed towards psychiatric research either, and there is no dedicated psychiatry journal in the country. According to Gadit (2006), the Journal of Clinical Psychiatry, which was once published regularly from Lahore, has ceased to exist and the first issue of the journal of Pakistan Psychiatric Society, called JPPS, was published in the year 2003 but was blocked politically and not reproduced again.

Prejudice and nepotism are the major factors contributing to decline. The system, which is already fragile, is further destabilised when locally trained psychiatrists in Pakistan are recruited internationally as consultants, leaving behind an increasing doctor:patient ratio.

In principle, I also agree with Dr Khan that one-off programmes should be discouraged and solutions which help in the longer run should take priority. After graduating in Karachi, I was involved in a community mental health initiative with our head of department in 2001-02, at Manora, an island near Karachi in the Arabian Sea with a population of 25000. The Manora Health Project was launched in 2000 and was working under the aegis of Department of Psychiatry, Hamdard University Hospital, with the objective of improving the general health of the population, but with a special emphasis on improvement of their mental health status. It was a centre which provided consultations with health professionals and medication free of charge. It also worked at training local mental health social workers. Referral to its parent private teaching hospital provided patients with further treatments at a discount. This greatly helped in identifying and managing numerous mental illnesses in that community which were either misunderstood or ignored owing to a lack of knowledge, stigma or financial incapability.

Last but not least, I think it is high time that in Pakistan there was a separate postgraduate college for each medical specialty.

Yasir Abbasi

$\mathrm{SHO}$ in Forensic Psychiatry, Rampton Hospital, Nottingham Healthcare NHS Trust, Porchester Road, Nottingham NG3 6AA, UK, email yasir.abbasi@nottshc.nhs.uk

Gadit, A. A. (2006) Mental health in Pakistan: where do we stand? Journal of the Pakistan Medical Association, 56, 198-199. 